\title{
GDP Purchasing Power Parity per Capita and Its Determinants: A Panel Data Analysis for BRICS
}

\author{
S. Venkata Seshaiah ${ }^{1}$, Trilochan Tripathy ${ }^{2}$ \\ ${ }^{1}$ Icfai Business School (IBS), IFHE, Hyderabad, India \\ ${ }^{2}$ XLRI-Xavier School of Management, Jamshedpur, India \\ Email: venkatas@ibsindia.org, trilochan@xlri.ac.in
}

How to cite this paper: Seshaiah, S.V. and Tripathy, T. (2018) GDP Purchasing Power Parity per Capita and Its Determinants: A Panel Data Analysis for BRICS. Theoretical Economics Letters, 8, 575-591. https://doi.org/10.4236/tel.2018.83040

Received: January 12, 2018

Accepted: February 11, 2018

Published: February 14, 2018

Copyright (c) 2018 by authors and Scientific Research Publishing Inc. This work is licensed under the Creative Commons Attribution International License (CC BY 4.0).

http://creativecommons.org/licenses/by/4.0/

(c) (i) Open Access

\begin{abstract}
This study examines the Gross Domestic product purchasing power parity per capita (GDP PPP per capita) and its determinants using the panel data method to test for unit roots in Brazil, Russia, India, China, and South Africa (BRICS). The main dependent variable in our study is GDP PPP per capita while the independent variables are real exchange rate, real interest rate, consumer price index (CPI), and money supply. We find strong evidence of a long-run relationship among the chosen variables. The co-integration equation reveals positive relationship between GDP PPP per capita and the real exchange rate, real interest rate, and money supply and a negative relationship between GDP PPP and CPI. Based on the VEC Granger Causality/Block Erogeneity Wald Tests, the study finds that the GDP PPP per capita is influenced by the exchange rate and CPI. However, based on the overall Chi-square test, the study shows strong evidence of an influence of all variables on GDP PPP per capita. We hope this study would help the policy makers to come up with appropriate policies to bring about homogeneity among the BRICS nations.
\end{abstract}

\section{Keywords \\ GDP, Panel Data Analysis, BRICS}

\section{Introduction}

The Purchasing Power Parity (PPP) Theory otherwise known as "Law of One Price" has remained an inconclusive debate in the academic and policy circles since it was coined by Cassel, G. [1]. The PPP is an economic theory that states residents of one country should be able to purchase the goods and services at the same price as residents of any other country over time. This theory has a linkage to goods and financial markets and the absence of PPP ignites the arbitrage op- 
portunity and in turn such arbitrage activities help establishing parity price for goods and services across the countries. It is an established fact that consumers and business persons often make comparisons between spending incomes, spot exchange rates, forward exchange rates, consumer price indices and interest between countries. These comparisons are made to understand the state of Purchasing Power Parity (PPP). Against this backdrop, more often policy makers face major issues such as how to maintain the optimal level of inflation; how to maintain the optimal level of exchange rates; how to manage the economic issues and policy responses; how to improve the quality of life; and how to manage the purchasing power parity and determinants of purchasing power parity. Substantial work has been done by experts to assess the validity of purchasing power parity in the long run taking either the indices of absolute purchasing parity or relative purchasing power parity as dependent variables. There are no dearths of literature that examine whether PPP is holding across the set of countries. However, even after extensive discourse on the PPP theory, it has remained a puzzle in the international finance literature. On the one hand a wide array of studies vehemently argue that validity of purchasing power parity is a myth and it is a theoretical conceptualization and on the other hand a handful of literature found evidence of validity of purchasing power parity both in the developed and emerging economies contexts.

However, there are not many studies which attempt to examine the factors determining the GDP PPP in emerging market space. Against this backdrop, this study makes an attempt to examine the influence of real exchange rates, real interest rates, and inflation on the movement of GDP PPP per capita across major emerging market spaces. The findings here suggest that the influence of real exchange rates, real interest rates, and inflation on the movement of GDP PPP per capita, exhibiting long-run relationships among the variables in question. It is evidenced that except money supply, all the variables influence the movement of GDP PPP per capita, thus confirming the theory. We hope this study would help the policy makers to come up with appropriate policies to bring about homogeneity among the BRICS nations.

The paper is organized under five broad sections. The section one captures the introduction. The broad contours of literature on PPP theory along with the gap and objectives of the study is captured in section two. Data and Methodology engaged in this study are delineated in the section three. The section four captures the results and discussion. The conclusion, contribution and limitations of the study is presented in the last section.

\section{Review of Literature}

John C.B. Cooper [2], using co-integration analysis, concluded that PPP does not hold in the long run for Australia, New Zealand, and Singapore. Thomas E. Schweigert [3], analyzed the nominal, real exchange rates, and purchasing power parity during the Guatemalan float for the period 1897-1922 and found a 
co-integration relationship among exchange rate, money supply, and the foreign consumer price index (CPI). The author observed a random walk with drift, implying a stationary real exchange rate. He then concluded that the real exchange behavior was inconsistent with theory. Salah A. Nusair [4] made an attempt to assess the validity of purchasing power parity for a sample of developing countries in the Asian Financial Crisis during current float. The author concluded that PPP does not hold in four out of the six Asian countries under study and also concluded that deviations in PPP are transitory. Ahmad Zubzid Baharumshah et al. [5] investigated the behavior of real exchange rates of six East-Asian countries along with their trading partners United States and Japan and used the ARDL model to test long-run PPP. The authors found no evidence of a weak form of PPP in the pre-crisis period but found small persistent PPP deviations during the post crisis period by concluding some form of PPP-oriented rule as a basis of their exchange rate policies.

Hsu-Ling Chang, Chi-Wei Su, Meng-Nan Zhu, and Pei Liu [6], examined the long-run purchasing power parity among BRICS using the Momentum Threshold Co-integration Test and the Engle Granger Test and found evidence of long-run PPP for BRICS and no co-integration based on the Engle-Granger Test. Finally, the authors concluded the importance of nominal exchange rates in eliminating the deviations from long-run PPP. Bulent Gologlu et al. [7], found evidence of quasi validity of purchasing power parity for 18 Turkish real exchange rate using the Panel Unit Root Test with structural breaks. Fizari Abu Hassan Asari, et al. [8] using the co-integration approach, studied the short run and long run determinants of purchasing power parity in Malaysia. The authors found the positive influence of real interest rates and consumer price index and the negative influence of real exchange rates and money supply in the movement of purchasing power parity of Malaysia. A. Oznur Umit [9] using the Traditional Unit Root Test and Unit Roots Test with structural breaks, assessed the stationarity of real exchange rate for five fragile countries-Brazil, India, Indonesia, Turkey, and South Africa. Based on the Traditional Unit Root Test, the author concluded that purchasing power parity does not hold true in these countries. Based on the results of Zivot-Andrews (one structural break)/Lee Strazicich (Two structural breaks) respectively, the author observed the validity of PPP for India and Brazil, and for India alone. The results of the Carrion-i-Silvestre (CS) Unit Root Test which allows five structural breaks revealed that PPP is not valid for India and South Africa and also concluded that Indians and South African banks are not under pressure to establish exchange rate stability.

Based on the backdrop of the paper, we make a modest attempt to use panel data analysis to assess the determinants of GDP PPP per capita for the BRICS countries. The main reasons for studying the BRICS countries emanates due to the following three reasons. These reasons are: 1) in a globalized world the production lag and demand lag have shortened, 2) across the countries people have started imitating the eating habits and production techniques, and 3) movement 
of goods and services due to technical as well economic substitution. We hope this study will help the policy makers to develop appropriate economic policies to integrate the BRICS economies. Our main equation that helps us determining GDP PPP is:

$$
\begin{aligned}
& \text { GDP PPP percapita } \\
& =f(\text { Realex changerate }(\mathrm{EX}), \text { Real interestrate }(\text { Int }), \\
& \quad \text { Consumer price index }(\mathrm{CPI}), \text { Money Supply (M3)). }
\end{aligned}
$$

\section{Data and Methodology}

\subsection{Nature and Sources of Data}

The present study employs yearly data on GDP PPP per capita, real interest rates, real exchange rates, consumer price index (CPI), and money supply over the period 1990-2016 from World Development Indicators. This data has been collected for Brazil, Russia, India, China, and South Africa (BRICS). Before conducting panel co-integration, we used Newey-West Automatic Bandwidth Selection and the Bartlett Kernel Summary Panel Unit Root Test, without which conclusions drawn from the co-integration estimation may not be valid. After confirming from the unit root and stationary tests that all the variables are non stationary in their levels form and stationary at the first difference, we proceed to co-integration analysis. For co-integration analysis we used Johansen Fisher Panel Co-integration. Pedroni and Kao Co-integration Tests are residual-based tests taken from the Engle Granger Two-step Test and both are one-way co-integration whereas the Johansen Fisher Panel Co-integration Test is a system-based co-integration test for the whole panel set. Further, we also estimated Granger Causality using VECM, Variance decomposition, VEC Granger Causality/Block Exogeneity Wald Tests, and pair-wise Granger Causality Tests. The details of these aforesaid methodologies used in this study are delineated hereunder sequentially.

\subsection{Panel Unit Root Test}

A wide array of literature delineates that individual time series based unit root tests have relatively lower power than the panel-based unit root tests. Some of the landmark study engages the panel based unit root tests in the context of the purchasing power parity (PPP) and growth convergence in macro panels using country data over time (Levin, Lin and Chu [10], Im, K.S. Persaran, M.H and Shin [11], and Breitung [12]. In this study we have focused on three types of panel unit root tests such as Levin, Lin and Chu (2002), Im, Pesaran and Shin; 2003, Fisher-Type test using ADF and PP-test (Maddala and Wu [13], These unit root methods also see more detail in Chaitip, P., Chaiboonsri, C. and N. Rangaswamy [14]. Levin, Lin and Chu (2002) delineate panel unit root test by consider the following basic ADF specification:

$$
\Delta Y_{i, t}=\left(\rho_{i}-1\right) Y_{i, t-1}+\sum_{j=1}^{\phi} \beta_{i, t} \Delta Y_{i, t-j}+\delta X_{i, t}+\varepsilon_{i, t}
$$


where, $\Delta Y_{i, t}$ is the difference terms associated with panel data variable $Y_{i, t}$; $\rho-1$ is $\ldots ; n$ is the number of lag order for difference terms; $X_{i, t}$ is the exogenous variable in model such as country fixed effects and time trend and $\varepsilon_{i, t}$ is the error term of equation. In the presence of autocorrelation and deterministic component in the above model is rewritten with the removal of these effects as follows:

$$
\Delta Y_{i, t}^{*}=\left(\rho_{i}-1\right) Y_{i, t-1}+\sum_{j=1}^{\phi} \beta_{i, t}^{*} \Delta Y_{i, t-j}+\delta^{*} X_{i, t}^{*}+\varepsilon_{i, t} .
$$

We can define the analogous $y_{i, t-1}^{*}$ using the second set of coefficients and it is presented in the following equation

$$
y_{i, t-1}^{*}=Y_{i, t-1}+\sum_{j=1}^{n} \beta_{i, t}^{*} \Delta Y_{i, t-j}+\delta X_{i, t}^{*} .
$$

While $\Delta Y_{i, t}^{*}$ and $y_{i, t-1}^{*}$ are transformed by dividing the regression standard error $\left(s_{i}\right)$ so as to get $\Delta Y_{i, t}^{+}$and $y_{i, t-1}^{+}$also can express more detail of these variable following that $\Delta Y_{i, t}^{+}=\Delta Y_{i, t}^{*} / s_{i}$ and $y_{i, t}^{+}=y_{i, t-1}^{*} / s_{i}$. Where $s_{i}$ are estimated standard errors from each $\mathrm{ADF}$ in Equation (9) and lastly an estimate of the coefficient $\alpha$ can be realized from the following Equation (5).

$$
\Delta Y_{i, t}^{+}=\left(\rho_{i}-1\right) y_{i, t}^{+}+\xi_{i, t}
$$

where resulting $\alpha$ coefficient in the above equation would be asymptotical having finite sample properties and normally distributed $[N \sim(0,1)]$ as per Levin and Lin (1993). However, if the $t$ statistic diverges to minus infinity, it has to be reentered and normalized to induce convergence towards a well-defined limiting distribution as demonstrated by Levin et al. (2002). Thus the modified statistics would be as follows:

$$
t^{*}=\left(t_{\phi}-N \tilde{T} \hat{S}_{N T} S T D(\hat{\Phi}) \mu_{m} T\right) / \sigma_{m} T
$$

where $\tilde{T}$ is the average effective sample size across the individual units and $\operatorname{STD}(\hat{\Phi})$ is the standard deviation of $\hat{\Phi}$ (see Levin et al., 2002).

$$
\hat{S}_{N T}=\frac{1}{N} \sum_{i=1}^{N} \hat{s}_{i}
$$

The Null hypothesis for the panel unit root test is:

$$
H_{0}: \Phi_{i}=\rho_{i}-1=0 .
$$

For $i=1, \cdots, N$.

That means, panel data has unit root (assumes common unit root process). The alternative hypothesis for the panel unit root test is:

$$
H_{1}: \Phi_{i}=\rho_{i}-1 \neq 0 .
$$

That means the panel data has not unit root. If $t$ is significant then conclusion that reject null hypothesis or panel data has not unit root. Otherwise If $t$ is not significant then conclusion that accept null hypothesis or panel data has unit root. 
Panel Unit root test of Im, Pesaran and Shin (1997 \& 2002) presented two group-mean panel unit root tests designed against the heterogeneous alternative. The test takes into account the individual specific autoregressive structures and individual specific variances to develop the test statistic. We have presented in detail the test procedure hereunder.

The model proposed to test panel unit root is:

$$
Y_{i t}=\alpha+\beta Y_{i t-1}+\varepsilon_{i t}
$$

where $t=1,2,3, \cdots, T$.

They use separate unit root test for the $N$ cross section units. Let $Y_{i t}$ be the observation on the ith cross-section unit at time $t$ and suppose that it is generated according to following simple dynamic linear heterogeneous panel data model and can be written in equation in Dicky Fuller format:

$$
Y_{i t}=\alpha+\beta Y_{i t-1}+\varepsilon_{i t}
$$

where $t=1,2, \cdots, T$.

The above first order Auto Regressive (AR) model contains a dependent variable $Y_{i t}$ and independent variable with its first order lag in the panel framework. In the panel framework, where $i$ varies from $1, \cdots, N$ are cross-section units; $t=1, \cdots, t$ are observed over periods; $\varepsilon_{i t}$ denotes the error term of equation. This can be presented in Augmented Dicky fuller model:

$$
\Delta Y_{i t}=\alpha_{i}+\beta_{i} \Delta Y_{i t-1}+\sum_{j=1}^{p i} \theta \Delta Y_{i t-j}+\varepsilon_{i t}
$$

where $t=1,2,3, \cdots, T$. The null hypothesis or unit root hypothesis of can now be expressed as $H_{0}: \beta=1$ (for all $i$ against the alternative hypothesis as $H_{1}: \beta<0$, $i=1,2, \cdots, N_{1}+1, N_{1}+2, \cdots, N$. The estimated t statistics for testing unit roots in individual series is:

$$
\bar{t}_{N T}=\frac{1}{N} \sum_{i=1}^{N} t_{i T}\left(p_{i} \theta_{i}\right) .
$$

The $\bar{t}_{N T}$ is the standardized and it is shown that the standardized $\bar{t}_{N T}$ statistic converges to the standard normal distribution as $N$ and $T \rightarrow \infty$. IPS (1997) showed that $\bar{t}_{N T}$ test has better performance when $\mathrm{N}$ and $\mathrm{T}$ are small. They proposed a cross-sectionally demeaned version of both test to be used in the case where the errors in different regressions contain a common time-specific component.

\subsection{Fisher-Type Test Using ADF and PP-Test (Maddala and Wu, 1999)}

Madala and Wu (1999) proposed the use of the Fisher (Pl) test which is based on combining the $\mathrm{P}$-values of the test-statistics for unit root in each cross-sectional unit. Let $p_{i}$ are $U[0,1]$ and independent, and $-2 \log _{e} p_{i}$ has a $\chi^{2}$ distribution with $2 N$ degree of freedom and can be written in the following Equation (12).

$$
\mathrm{P} 1=-2 S N_{i}=\log _{e} p_{i}
$$

where $\mathrm{Pl}=$ Fisher $(\mathrm{Pl})$ panel unit root test, $N=$ all $N$ cross-section and 
$-2 S N_{i}=\log _{e} p_{i}$ it has a $\chi^{2}$ distribution with $2 N$ degree of freedom.

Fisher (Pl) Chi Square panel unit root test has non-stationary as null hypothesis as well as to show below that:

$\mathrm{H}_{0}$ : panel data has unit root (assumes individual unit root process), against the alternatives.

$\mathrm{H}_{1}$ : panel data has not unit root.

If both Fisher (Pl) Chi-square panel unit root test and Choi Z-statistics panel unit root test are significant then conclusion that reject null hypothesis or panel data has not unit root. Otherwise both If Fisher (Pl) Chi-square panel unit root test is not significant then conclusion that accept null hypothesis or panel data has unit root.

\subsection{Panel Cointegration Test}

Johansen (1988) proposes two different approaches; one of them is the likelihood ratio trace statistics and the other one is maximum eigenvalue statistics, to determine the presence of cointegration vectors in non-stationary time series. The trace statistics and maximum eigenvalue statistics have shown in Equations ((13) and (14)) respectively.

$$
\begin{gathered}
\lambda_{\text {trace }}(r)=-T \sum_{i=i+r}^{n} \ln \left(1-\widehat{\lambda}_{i}\right) \\
\lambda_{\max }(r, r+1)=-T \ln \left(1-\widehat{\lambda_{r+1}}\right) .
\end{gathered}
$$

For the trace statistic test the null hypothesis is to check for at most $\mathrm{r}$ cointegrating vectors against the alternative Hypothesis: Full rank $r=n$ cointegrating vector. The Null hypothesis for the maximum eigenvalue statistics is to be checked for the for $r$ cointegrating vectors against the alternative hypothesis of $r$ +1 cointegrating vectors.

Using Johansens [15] test for cointegration for Maddala and Wu (1999) consider Fisher's [16] suggestion to combine individual tests to propose an alternative to the two previous tests for testing the cointegration in the full panel by combining individual cross section tests for cointegration. If $\mu \mathrm{i}$ is the $\mathrm{p}$ value from an individual cointegration test for cross section i then under the null hypothesis for the whole panel cointegration is as follows:

$$
-2 \sum_{i=1}^{n} \log _{e}\left(\Pi_{i}\right) \sim \chi_{2 N}^{2} .
$$

This is having a chi square distribution with $2 N$ degrees of freedom. The null and alternative hypotheses are the same as in the Im, Pesaran and Shin (1997 \& 2002) test. Applying the ADF estimation equation in each cross-section, we can compute the ADF t-statistic for each individual series, find the corresponding $\mathrm{p}$-value from the empirical distribution of ADF t-statistic and compute the Fisher-test statistics and compare it with the appropriate $\chi^{2}$ critical value. The Maddala-Wu (1999) test using Fisher's test is suitable due to the fact that: 1) this test can be performed with any unit root test on a single time-series, and 2) this does not 
require a balanced panel as the Im, Pesaran and Shin [11] test does, so T can differ over cross sections.

\subsection{VAR Specification}

$$
\begin{aligned}
y_{i t}= & b_{10}-b_{12} x_{i t}+b_{12} z_{i t}+b_{12} m_{i t}+b_{12} n_{i t}+c_{11} y_{i t-1} \\
& +c_{12} x_{i t-1}+c_{12} z_{i t-1}+c_{12} m_{i t-1}+c_{12} n_{i t-1}+\varepsilon_{y t} \\
x_{i t}= & b_{20}-b_{12} y_{i t}+b_{12} z_{i t}+b_{12} m_{i t}+b_{12} n_{i t}+c_{11} y_{i t-1} \\
& +c_{12} x_{i t-1}+c_{12} z_{i t-1}+c_{12} m_{i t-1}+c_{12} n_{i t-1}+\varepsilon_{x t} \\
z_{i t}= & b_{30}-b_{12} y_{i t}+b_{12} x_{i t}+b_{12} m_{i t}+b_{12} n_{i t}+c_{11} y_{i t-1} \\
& +c_{12} x_{i t-1}+c_{12} z_{i t-1}+c_{12} m_{i t-1}+c_{12} n_{i t-1}+\varepsilon_{z t} \\
m_{i t}= & b_{40}-b_{12} x_{i t}+b_{12} z_{i t}+b_{12} y_{i t}+b_{12} n_{i t}+c_{11} y_{i t-1} \\
& +c_{12} x_{i t-1}+c_{12} z_{i t-1}+c_{12} m_{i t-1}+c_{12} n_{i t-1}+\varepsilon_{m t} \\
n_{i t}= & b_{50}-b_{12} x_{i t}+b_{12} z_{i t}+b_{12} m_{i t}+b_{12} y_{i t}+c_{11} y_{i t-1} \\
& +c_{12} x_{i t-1}+c_{12} z_{i t-1}+c_{12} m_{i t-1}+c_{12} n_{i t-1}+\varepsilon_{n t}
\end{aligned}
$$

The error series are distributed with i.i.d $\left(0, \sigma_{\varepsilon i}^{2}\right)$ and covariance across the errors are 0.

where,

$y$ indicates per capita GDP $\mathrm{ppp}_{\text {for }}$ fhe country $i$ in the year $t$,

$x_{i t}$ indicates Real Exchange for the country $i$ in the year $t$,

$Z_{i t}$ indicates the real interest rate for the country $i$ in the year $t$,

$m_{i t}$ indicates Consumer Price Index (CPI) for the country $i$ in the year $t$,

$n_{i t}$ indicates the money supply (M3) for the country $i$ in the year $t$.

While determining the optimal lag length for the VAR, we have conducted the following LR tests and the information criteria statistics. The LR tests are as follows:

$$
\mathrm{LR}=(T-m)\left(\ln \left|\Sigma_{r}\right|-\ln \left|\Sigma_{u}\right|\right) \sim \chi^{2}(q)
$$

where $T=\#$ observations (after accounting for lags), $m=$ number of parameters estimated in each equation of the unrestricted system, including the constant. $\ln \left|\Sigma_{r}\right|$ natural log of the determinant of the covariance matrix of residuals of the restricted system. $q=$ total number of restrictions in the system (=number of lags times $n^{2}$ ) and $n$ =number of variables (or equations).If the LR statistics < critical value, reject the null of the restricted system.

Further, we have also used the following Information criteria

$$
\begin{gathered}
\mathrm{AIC}=T \ln |\Sigma|+2 N \\
\mathrm{SBC}=T \ln |\Sigma|+N \ln T .
\end{gathered}
$$

Choose the \# lag that minimizes the criteria. Note that these criteria are not tests; they mainly indicate goodness of fit of alternatives, so used this as complements to the LR tests.

\subsection{Vector Error Correction Model}

A Vector Error Correction Model (VECM) can lead to a better understanding of 
the nature of any non-stationarity among the different component series and can also improve longer term forecasting over an unconstrained model. The VECM $(p)$ form is written as:

$$
\begin{aligned}
\Delta y_{i t}= & c_{10}-\phi_{11}\left(y_{i t}-\gamma_{0}-\gamma_{1} x_{i t-1}-\gamma_{2} z_{i t-1}-\gamma_{3} m_{i t-1}-\gamma_{4} n_{i t-1}\right)+\sum_{i=1}^{j} \beta_{1, j} \Delta y_{1 t-i} \\
& +\sum_{i=1}^{j} \beta_{2 j} \Delta x_{i t-i}+\sum_{i=1}^{j} \beta_{3 j} \Delta z_{i t-i}+\sum_{i=1}^{j} \beta_{4 j} \Delta m_{i t-i}+\sum_{i=1}^{j} \beta_{5, j} \Delta n_{i t-i}+\varepsilon_{y t} \\
\Delta x_{i t}= & d_{10}-\phi_{12}\left(x_{i t}-\delta_{0}-\delta_{1} y_{i t-1}-\delta_{2} z_{i t-1}-\delta_{3} m_{i t-1}-\delta_{4} n_{i t-1}\right)+\sum_{i=1}^{j} \varphi_{1, j} \Delta x_{1 t-i} \\
& +\sum_{i=1}^{j} \varphi_{2 j} \Delta y_{i t-i}+\sum_{i=1}^{j} \varphi_{3 j} \Delta z_{i t-i}+\sum_{i=1}^{j} \varphi_{4 j} \Delta m_{i t-i}+\sum_{i=1}^{j} \varphi_{5, j} \Delta n_{i t-i}+\varepsilon_{x t} \\
\Delta z_{i t}= & d_{10}-\phi_{13}\left(z_{i t}-\eta_{0}-\eta_{1} y_{i t-1}-\eta_{2} x_{i t-1}-\eta_{3} m_{i t-1}-\eta_{4} n_{i t-1}\right)+\sum_{i=1}^{j} \kappa_{1, j} \Delta x_{1 t-i} \\
& +\sum_{i=1}^{j} \kappa_{2 j} \Delta y_{i t-i}+\sum_{i=1}^{j} \kappa_{3 j} \Delta z_{i t-i}+\sum_{i=1}^{j} \kappa_{4 j} \Delta m_{i t-i}+\sum_{i=1}^{j} \kappa_{5, j} \Delta n_{i t-i}+\varepsilon_{z t} \\
\Delta m_{i t}= & f_{10}-\phi_{14}\left(m_{i t}-\mu_{0}-\mu_{1} y_{i t-1}-\mu_{2} x_{i t-1}-\mu_{3} m_{i t-1}-\mu_{4} n_{i t-1}\right)+\sum_{i=1}^{j} v_{1, j} \Delta x_{1 t-i} \\
& +\sum_{i=1}^{j} v_{2 j} \Delta y_{i t-i}+\sum_{i=1}^{j} v_{3 j} \Delta z_{i t-i}+\sum_{i=1}^{j} v_{4 j} \Delta m_{i t-i}+\sum_{i=1}^{j} v_{5, j} \Delta n_{i t-i}+\varepsilon_{m t} \\
\Delta n_{i t}= & g_{10}-\phi_{15}\left(n_{i t}-\varpi_{0}-\varpi_{1} y_{i t-1}-\varpi_{2} x_{i t-1}-\varpi_{3} z_{i t-1}-\varpi_{4} m_{i t-1}\right)+\sum_{i=1}^{j} \psi_{1, j} \Delta x_{1 t-i} \\
& \sum_{i=1}^{j} \Delta y_{i t-i}+\sum_{i=1}^{j} \psi_{3 j} \Delta z_{i t-i}+\sum_{i=1}^{j} \psi_{4 j} \Delta m_{i t-i}+\sum_{i=1}^{j} \psi_{5, j} \Delta n_{i t-i}+\varepsilon_{n t}
\end{aligned}
$$

where $\Delta$ is the differencing operator.

\subsection{VAR Causality (Block Exogeneity) Wald Tests}

We use VAR causality test to establish any causal relationship among the variables. In VAR model the causality can be evaluated by examining the joint significance of lagged coefficients of one variable in the equation of another variable. This kind of significance testing is called the Block significance test and it can be performed with the usual $\mathrm{F}$ test or Wald test used for evaluation of parameter restrictions.

\section{Results and Discussion}

\subsection{Descriptive Statistics: (We Need to Put This Statistics)}

It is observed from the Table 1, that the growth in GDP PPP is almost two times greater than the growth in Money supply, Consumer price index and interest rates. It is also observed that the volatility in exchange rate and Consumer price index is greater than the other variables under the present study. Based on the Jarque-Bera test it is observed that except for the money supply the null of normality is rejected for all other variables under consideration. Finally it may concluded 
Table 1. Descriptive statistics.

\begin{tabular}{cccccc}
\hline & GDP PPP & MONEY SUPPLY & CPI & EX & INT \\
\hline Mean & 3.909554 & 1.796403 & 1.603216 & 0.834446 & 1.218824 \\
Median & 4.026903 & 1.789559 & 1.844096 & 0.901646 & 1.119476 \\
Maximum & 4.400436 & 2.318703 & 2.210055 & 1.827339 & 2.505568 \\
Minimum & 3.183671 & 1.250306 & -3.049202 & -4.529336 & 0.638489 \\
Std. Dev. & 0.328925 & 0.240831 & 0.844358 & 0.886179 & 0.353498 \\
Skewness & -0.671215 & 0.004052 & -3.558362 & -3.175447 & 0.776623 \\
Kurtosis & 2.316447 & 2.824383 & 16.08376 & 18.00593 & 3.274339 \\
Jarque-Bera & 12.76517 & 0.173852 & 1247.808 & 1493.505 & 13.99407 \\
Probability & 0.001691 & 0.916745 & 0.000000 & 0.000000 & 0.000915 \\
Sum & 527.7898 & 242.5144 & 216.4342 & 112.6502 & 164.5413 \\
Sum Sq. Dev. & 14.49765 & 7.771926 & 95.53412 & 105.2319 & 16.74473 \\
Observations & 135 & 135 & 135 & 135 & 135 \\
\hline
\end{tabular}

that irrespective of the fluctuation in money supply, consumer price index, exchange rates and interest rate the growth in GDP PPP is greater indicating the influence of informal economy.

\subsection{Panel Unit Root Tests Results}

We have used Newey-West Automatic Bandwidth Selection and Bartlett KernelSummary Panel Unit Root Test to find whether the unit root exists, based on the test results reported in Table 2. We have used two broad categories of panel unit root test processes such as common unit root process proposed by Levin Lin and Chu (2002) and individual unit root process proposed by Im, Pesaran and Shin(1997 \& 2002). Following these processes, we have used three types of panel unit root tests such as: 1) Im, Pesaran and shin panel unit root test; 2) second is Fisher type test-the ADFF is her Chi-square test; and 3) the Fisher type test-the PP Fisher Chi-square panel unit root test. We have carried out these tests at level and at first difference as well. Irrespective of the methods used in this study for the panel unit root tests suggest that the variables at level are found to have panel unit roots both at cross section and individual levels. However, the first differences of all these variables are seen to have been no unit roots. That means the panel set up is observed to be stationary at first difference. Thus, here onwards all other examinations have been carried out at first difference series.

\subsection{Johansen Fisher Panel Co-Integration Test Results}

We have performed Johansen Fisher Panel Co-integration to see whether any combination of the variables is co-integrated. The results are reported in Table 3. It may be observed from Table 3 that the GDP PPP per capita exhibits a longrun relationship with the variables under study. The results of the VEC Granger Causality/Block Exogeneity Wald Tests reported in Table 4 suggest the influence 
Table 2. Panel unit root test: summary-levels.

\begin{tabular}{|c|c|c|c|c|}
\hline Method & Statistic & Prob. ${ }^{* *}$ & Cross-sections & Obs \\
\hline \multicolumn{5}{|c|}{ Null: Unit root (assumes common unit root process) } \\
\hline Levin, Lin \& Chu $t^{*}$ & -1.16456 & 0.1221 & 5 & 125 \\
\hline \multicolumn{5}{|c|}{ Null: Unit root (assumes individual unit root process) } \\
\hline Im, Pesaran and Shin W-stat & 1.80485 & 0.9645 & 5 & 125 \\
\hline ADF-Fisher Chi-square & 4.33450 & 0.9310 & 5 & 125 \\
\hline PP-Fisher Chi-square & 2.18608 & 0.9947 & 5 & 130 \\
\hline \multicolumn{5}{|c|}{ Panel unit root test: Summary first difference } \\
\hline Method & Statistic & Prob. ${ }^{* *}$ & Cross-sections & Obs \\
\hline \multicolumn{5}{|c|}{ Null: Unit root (assumes common unit root process) } \\
\hline Levin, Lin \& Chu $t^{*}$ & -2.11003 & 0.0174 & 5 & 120 \\
\hline \multicolumn{5}{|c|}{ Null: Unit root (assumes individual unit root process) } \\
\hline Im, Pesaran and Shin W-stat & -2.67515 & 0.0037 & 5 & 120 \\
\hline ADF-Fisher Chi-square & 23.9785 & 0.0077 & 5 & 120 \\
\hline PP-Fisher Chi-square & 29.3166 & 0.0011 & 5 & 125 \\
\hline
\end{tabular}

Table 3. Johansen fisher panel cointegration test. Series: ppp ex lr pr money supply.

\begin{tabular}{ccccc}
\hline Hypothesized & $\begin{array}{c}\text { Fisher Stat. } \\
\text { (from trace test) }\end{array}$ & Prob. & $\begin{array}{c}\text { Fisher Stat. } \\
\text { (from max-eigen test) }\end{array}$ & Prob \\
\hline No. of CE(s) & 174.1 & 0.0000 & 99.84 & 0.0000 \\
At most 1 & 104.9 & 0.0000 & 71.62 & 0.0000 \\
At most 2 & 48.75 & 0.0005 & 29.26 & 0.0011 \\
At most 3 & 28.64 & 0.1089 & 20.83 & 0.0223 \\
At most 4 & 24.83 & 0.0057 & 24.83 & 0.0057 \\
\hline
\end{tabular}

${ }^{\star}$ Probabilities are computed using asymptotic Chi-square distribution.

of exchange rates and CPI on the movement of GDP PPP per capita and no influence of interest rates and money supply. However, based on the chi-squire test, it is also observed that GDP PPP per capita was influenced by the variables under consideration. It is also observed that the exchange rate, real interest rate, CPI, and money supply were influenced by all the variables in question. However, PPP has not influenced the exchange rates, interest rates, and CPI in isolation. In case of money supply only CPI has been influenced. In an attempt to understand the direction and magnitude of the relationship, the elasticity results have been extracted and expressed in the following equation form.

$\mathrm{PPP}=-3.697876+0.551649 \mathrm{Ex}+0.502476 \mathrm{Int}-2.7666 \mathrm{CPI}+1.891337 \mathrm{M} 3$

\section{$[4.81495] \quad[2.34151] \quad[-19.9918] \quad[5.82120]$}


Table 4. VEC granger causality/block exogeneity wald tests.

\begin{tabular}{|c|c|c|c|}
\hline \multicolumn{4}{|c|}{ Dependent variable: $\mathrm{D}\left(\mathrm{GDP}_{\mathrm{PPP}}\right)$} \\
\hline Excluded & Chi-sq & $\mathrm{df}$ & Prob. \\
\hline $\mathrm{D}(\mathrm{EX})$ & 8.570954 & 2 & 0.0138 \\
\hline D (INT) & 0.961925 & 2 & 0.6182 \\
\hline $\mathrm{D}(\mathrm{CPI})$ & 6.588302 & 2 & 0.0371 \\
\hline D (MONEY SUPPLY) & 0.319711 & 2 & 0.8523 \\
\hline All & 15.62273 & 8 & 0.0481 \\
\hline \multicolumn{4}{|c|}{ Dependent variable: D (EX) } \\
\hline Excluded & Chi-sq & $\mathrm{df}$ & Prob. \\
\hline $\mathrm{D}(\mathrm{PPP})$ & 1.220023 & 2 & 0.5433 \\
\hline $\mathrm{D}(\mathrm{INT})$ & 6.566046 & 2 & 0.0375 \\
\hline $\mathrm{D}(\mathrm{CPI})$ & 9.900178 & 2 & 0.0071 \\
\hline D (MONEY SUPPLY) & 97.99322 & 2 & 0.0000 \\
\hline All & 114.4634 & 8 & 0.0000 \\
\hline \multicolumn{4}{|c|}{ Dependent variable: D (INT) } \\
\hline Excluded & Chi-sq & $\mathrm{df}$ & Prob. \\
\hline $\mathrm{D}(\mathrm{PPP})$ & 1.576827 & 2 & 0.4546 \\
\hline $\mathrm{D}(\mathrm{EX})$ & 43.44022 & 2 & 0.0000 \\
\hline $\mathrm{D}(\mathrm{CPI})$ & 37.10316 & 2 & 0.0000 \\
\hline D (MONEY SUPPLY) & 0.329470 & 2 & 0.8481 \\
\hline All & 57.75642 & 8 & 0.0000 \\
\hline \multicolumn{4}{|c|}{ Dependent variable: D (CPI) } \\
\hline Excluded & Chi-sq & df & Prob. \\
\hline $\mathrm{D}(\mathrm{PPP})$ & 3.230645 & 2 & 0.1988 \\
\hline $\mathrm{D}(\mathrm{EX})$ & 13.18095 & 2 & 0.0014 \\
\hline $\mathrm{D}(\mathrm{INT})$ & 3.263344 & 2 & 0.1956 \\
\hline D (MONEY SUPPLY) & 52.33879 & 2 & 0.0000 \\
\hline All & 114.9840 & 8 & 0.0000 \\
\hline \multicolumn{4}{|c|}{ Dependent variable: D (MONEY SUPPLY) } \\
\hline Excluded & Chi-sq & $\mathrm{df}$ & Prob. \\
\hline $\mathrm{D}(\mathrm{PPP})$ & 2.906418 & 2 & 0.2338 \\
\hline $\mathrm{D}(\mathrm{EX})$ & 1.389691 & 2 & 0.4992 \\
\hline $\mathrm{D}(\mathrm{INT})$ & 4.450634 & 2 & 0.1080 \\
\hline $\mathrm{D}(\mathrm{CPI})$ & 9.898612 & 2 & 0.0071 \\
\hline All & 31.87754 & 8 & 0.0001 \\
\hline
\end{tabular}

Note: Where $\mathrm{D}\left(\mathrm{GDP}_{\mathrm{PPP}}\right)=\Delta y_{i t}, \mathrm{D}(\mathrm{EX})=\Delta x_{i t}, \mathrm{D}(\mathrm{INT})=\Delta z_{i t}, \mathrm{D}(\mathrm{CPI})=m_{i t}$ and $\mathrm{D}(\mathrm{MONEY}$ SUPPLY $)=\Delta n_{i t}$. 
It may be observed from the equation that GDP PPP per capita exhibits a positive relationship with the real exchange rate, indicating that a $1 \%$ increase in the real exchange rate increases the GDP PPP per capita by $0.551649 \%$. The result is inconsistent with theory. As per the theory, interest rates and purchasing power parity have a positive relationship because the real interest rate is inflationary adjusted interest rate. As the real interest rate increases, the cost of borrowing increases. This makes the money costlier to borrow, which reduces money supply and hence inflation reduces. This phenomenon boosts the GDP PPP per capita. As per our study, a $1 \%$ increase in the real interest rate boosts the GDP PPP per capita by $0.502476 \%$, which confirms the theory. It is observed that the elasticity of CPI is very high, indicating that a $1 \%$ increase in CPI reduces the GDP PPP by 2.7661, confirming the theory. Theoretically, the relationship between GDP PPP per capita and money supply is negative. But in our study, we found that a $1 \%$ increase in money supply boosts the GDP PPP per capita by $1.891337 \%$ which is inconsistent with theory. This might be due to the non influence of monetary policies or may be because of the Informal economy.

\subsection{Variance Decomposition Results}

Further variance decomposition results from Table 5 reveal that exchange rate,

Table 5. Variance decomposition of PPP.

\begin{tabular}{|c|c|c|c|c|c|c|}
\hline Period & S.E. & PPP & EX & INT & CPI & $\begin{array}{l}\text { MONEY } \\
\text { SUPPLY }\end{array}$ \\
\hline 1 & 0.011771 & 100.0000 & 0.000000 & 0.000000 & 0.000000 & 0.000000 \\
\hline 2 & 0.021883 & 97.24894 & 1.192626 & 0.105186 & 1.359665 & 0.093588 \\
\hline 3 & 0.033215 & 95.89054 & 1.780430 & 0.072373 & 1.827515 & 0.429138 \\
\hline 4 & 0.044909 & 95.42376 & 1.994794 & 0.069944 & 2.012782 & 0.498720 \\
\hline 5 & 0.056832 & 95.48071 & 1.978663 & 0.057430 & 2.014446 & 0.468751 \\
\hline 6 & 0.068641 & 95.56408 & 1.934840 & 0.044794 & 2.024154 & 0.432128 \\
\hline 7 & 0.080268 & 95.64474 & 1.874451 & 0.036044 & 2.034320 & 0.410445 \\
\hline 8 & 0.091660 & 95.73541 & 1.801313 & 0.030271 & 2.040942 & 0.392065 \\
\hline 9 & 0.102778 & 95.82667 & 1.728676 & 0.025580 & 2.047668 & 0.371405 \\
\hline 10 & 0.113585 & 95.90824 & 1.663811 & 0.021713 & 2.055018 & 0.351215 \\
\hline \multicolumn{7}{|c|}{ Variance Decomposition of EX: } \\
\hline Period & S.E. & PPP & EX & INT & CPI & $\begin{array}{l}\text { MONEY } \\
\text { SUPPLY }\end{array}$ \\
\hline 1 & 0.072982 & 12.78404 & 87.21596 & 0.000000 & 0.000000 & 0.000000 \\
\hline 2 & 0.146770 & 15.36788 & 68.77804 & 0.290822 & 0.929939 & 14.63331 \\
\hline 3 & 0.216343 & 14.37984 & 60.48713 & 1.839867 & 2.555188 & 20.73797 \\
\hline 4 & 0.271016 & 12.85242 & 59.76473 & 2.398366 & 4.174601 & 20.80989 \\
\hline 5 & 0.318714 & 11.85761 & 60.81669 & 2.355189 & 5.505064 & 19.46545 \\
\hline 6 & 0.360523 & 11.24967 & 61.28364 & 2.376589 & 6.142977 & 18.94712 \\
\hline 7 & 0.396370 & 10.87794 & 61.18421 & 2.505754 & 6.483060 & 18.94904 \\
\hline 8 & 0.428307 & 10.61453 & 61.11770 & 2.561969 & 6.874790 & 18.83101 \\
\hline
\end{tabular}


Continued

\begin{tabular}{|c|c|c|c|c|c|c|}
\hline 9 & 0.458155 & 10.39570 & 61.15136 & 2.560758 & 7.291468 & 18.60071 \\
\hline 10 & 0.485851 & 10.20913 & 61.14651 & 2.578828 & 7.603995 & 18.46154 \\
\hline \multicolumn{7}{|c|}{ Variance Decomposition of INT: } \\
\hline Period & S.E. & PPP & EX & INT & CPI & MONEY \\
\hline 1 & 0.099205 & 7.282522 & 1.606786 & 91.11069 & 0.000000 & 0.000000 \\
\hline 2 & 0.134334 & 10.02659 & 3.236699 & 86.66533 & 0.024844 & 0.046529 \\
\hline 3 & 0.149220 & 8.359334 & 3.847223 & 83.98558 & 3.490909 & 0.316950 \\
\hline 4 & 0.166689 & 6.758303 & 5.896661 & 82.59224 & 4.430053 & 0.322745 \\
\hline 5 & 0.185762 & 5.521387 & 5.253826 & 84.90322 & 3.590384 & 0.731179 \\
\hline 6 & 0.200034 & 4.765403 & 4.875212 & 86.47113 & 3.157718 & 0.730534 \\
\hline 7 & 0.212726 & 4.275537 & 5.532287 & 86.27379 & 3.235148 & 0.683238 \\
\hline 8 & 0.226650 & 3.864859 & 6.145412 & 86.05677 & 3.117924 & 0.815036 \\
\hline 9 & 0.240321 & 3.524975 & 6.213071 & 86.41345 & 2.859551 & 0.988953 \\
\hline 10 & 0.252425 & 3.316942 & 6.353562 & 86.58866 & 2.713528 & 1.027306 \\
\hline \multicolumn{7}{|c|}{ Variance Decomposition of CPI: } \\
\hline Period & S.E. & PPP & EX & INT & CPI & $\begin{array}{l}\text { MONEY } \\
\text { SUPPLY }\end{array}$ \\
\hline 1 & 0.052210 & 3.553367 & 15.94145 & 10.08193 & 70.42325 & 0.000000 \\
\hline 2 & 0.083371 & 15.00432 & 20.34301 & 7.634971 & 38.56772 & 18.44998 \\
\hline 3 & 0.111676 & 14.91196 & 25.15893 & 4.271268 & 21.49544 & 34.16241 \\
\hline 4 & 0.131941 & 12.11698 & 29.55239 & 3.109580 & 16.64921 & 38.57185 \\
\hline 5 & 0.146260 & 10.08266 & 33.45899 & 2.537674 & 15.41620 & 38.50448 \\
\hline 6 & 0.157221 & 8.740263 & 35.69308 & 2.238417 & 14.88054 & 38.44770 \\
\hline 7 & 0.165789 & 7.875605 & 36.35811 & 2.037680 & 14.60518 & 39.12343 \\
\hline 8 & 0.172966 & 7.335294 & 36.39538 & 1.910584 & 14.71792 & 39.64082 \\
\hline 9 & 0.179562 & 7.010586 & 36.29397 & 1.846474 & 15.13308 & 39.71590 \\
\hline 10 & 0.185695 & 6.869087 & 36.06086 & 1.803560 & 15.56706 & 39.69943 \\
\hline \multicolumn{7}{|c|}{ Variance Decomposition of MONEY SUPPLY: } \\
\hline Period & S.E. & PPP & EX & INT & $\mathrm{CPI}$ & $\begin{array}{l}\text { MONEY } \\
\text { SUPPLY }\end{array}$ \\
\hline 1 & 0.037786 & 8.060626 & 0.039572 & 0.029771 & 13.71085 & 78.15918 \\
\hline 2 & 0.055907 & 5.008217 & 0.090398 & 1.817608 & 20.99330 & 72.09048 \\
\hline 3 & 0.063163 & 4.045772 & 0.073563 & 2.098877 & 25.80237 & 67.97942 \\
\hline 4 & 0.067623 & 3.721045 & 0.074397 & 1.864183 & 28.43005 & 65.91033 \\
\hline 5 & 0.072265 & 3.349404 & 0.070980 & 1.694626 & 28.69511 & 66.18988 \\
\hline 6 & 0.077216 & 3.052993 & 0.136782 & 1.672915 & 28.26823 & 66.86908 \\
\hline 7 & 0.081817 & 2.903230 & 0.154945 & 1.603730 & 28.55931 & 66.77879 \\
\hline 8 & 0.086166 & 2.830630 & 0.139829 & 1.508697 & 29.13382 & 66.38702 \\
\hline 9 & 0.090383 & 2.817575 & 0.127222 & 1.457242 & 29.31208 & 66.28589 \\
\hline 10 & 0.094424 & 2.852806 & 0.121398 & 1.431241 & 29.28916 & 66.30539 \\
\hline
\end{tabular}


interest rate, prices, and money supply result in a variance in GDP PPP per capita by $1.66 \%, 0.021 \%, 2.06 \%$, and $0.35 \%$ respectively with a lag of 10 periods. It is also observed that that variance in the exchange rate was influenced by GDP PPP per capita $(10.21 \%)$, interest rates $(2.57 \%)$, consumer price index (CPI) (7.61\%), and money supply (18.46\%). The variance in interest rate was influenced by GDP PPP per capita (3.32\%) followed by exchange rate (6.36\%), CPI (2.72), and money supply (1.03\%). It is also observed that the variance in CPI was influenced the most by money supply $(39.69 \%)$, followed by exchange rate (36.06\%), GDP PPP per capita (6.87\%), and interest rate (1.80\%) with a lag of 10 periods. With a lag of 10 periods, the variance in money supply was influenced by GDP PPP per capita $(2.85 \%)$, exchange rates $(0.12 \%)$, interest rate $(1.43 \%)$, and CPI (29.29\%).

\section{Conclusions}

We make a modest attempt to use panel data analysis to assess the determinants of GDP PPP per capita for Brazil, Russia, India, China, and South Africa in cross section over the period 1990-2016. We conjecture that these countries are to be studied in a panel framework due to three reasons such as in a globalized world the production lag and demand lag have shortened, across the countries people have started imitating the eating habits and production techniques, and movement of goods and services due to technical as well economic substitution. The main dependent variable in our study is GDP PPP per capita while the independent variables are real exchange rate, real interest rate, consumer price index (CPI), and money supply. We observed via panel unit root test that the series under panel framework are observed to have unit root at its level but the series are free from unit roots at first difference. It is also evidenced that there is a long-run relationship among the chosen variables. The co-integration equation reveals positive relationship between GDP PPP per capita and the real exchange rate, real interest rate, and money supply and a negative relationship between GDP PPP and CPI. Based on the VEC Granger Causality/Block Erogeneity Wald Tests, the study finds that the GDP PPP per capita is influenced by the exchange rate and CPI. However, based on the overall Chi-square test, the study shows strong evidence of an influence of all variables on GDP PPP per capita. Thus we have found evidence of the influence of real exchange rates, real interest rates, and CPI on the movement of GDP PPP per capita, exhibiting long-run relationships among the variables in question. Except money supply, all the variables influence the movement of GDP PPP per capita, thus confirming the theory. The positive influence of money supply on GDP PPP evidenced in this study could be due to the fact that monetary policy is no that effective due to the presence of large informal sectors in these economies.

The result here implies that differences in transportation costs, taxes, and tariffs among emerging economies are narrowing down and thus perhaps GDP PPP is evidenced in the emerging market space. Finally, the implications of any 
reassessment of the long-run GDP PPP growth rate for current macroeconomic policies in these economies need to be put into context both in terms of the size of the reassessment and the difference between the current policy rate and the long-run neutral rate. We hope this study would help the policy makers to come up with appropriate policies to bring about homogeneity among the BRICS nations. This study can be replicated in the other economies. This study is not also free from limitations. Though these economies are in the emerging market space still the nature and informality across the countries remain different and thus building a panel model may be questioned. However, no doubt this study has widened the scope to understand the GDP PPP for other set of countries with some similarity across them.

\section{References}

[1] Cassel, G. (1981) Abnormal Deviations in International Exchanges. The Economic Journal, 28, 413-415. https://doi.org/10.2307/2223329

[2] Cooper, J.C.B. (1994) Purchasing Power Parity: A Cointegration Analysis of the Australian, New Zeland and Singaporean Currencies. Applied Economics Letters, 1, 167-171. https://doi.org/10.1080/135048594357934

[3] Schweigert, T.E. (2002) Nominal and Real Exchange Rates and Purchasing Power Parity during the Guatemalan Float, 1897-1922. Journal of Economic Development, 27, 127-142.

[4] Nusar, S.A. (2003) Testing the Validity of Purchasing Power Parity for Asian Countries during the Current Float. Journal of Economic Development, 28, 129-147.

[5] Baharumshah, A.Z., Tze-Haw, C. and Fountas, S. (2008) Re-Examining Purchasing Power Parity for East Asian Currencies: 1976-2002. Applied Financial Economics, 18, 75-85. https://doi.org/10.1080/09603100601018856

[6] Chang, H.-L., Su, C.-W., Zhu, M.-N. and Liu, P. (2010) Long-Run Purchasing Power Parity and Asymmetric Adjustment in BRICs. Applied Economics Letters, 17, 1083-1087. https://doi.org/10.1080/00036840902817458

[7] Gologlu, B., Ispira, S. and Okat, D (2011) Testing the Validity of Quasi PPP Hypothesis: Evidence from a Recent Panel Root Test with Structural Breaks. Applied Economics Letters, 18, 1817-1822. https://doi.org/10.1080/13504851.2011.564124

[8] Asari, F.A.H., Miseman, M.R., Narazidah, N.H., Mohamad, Z. and Kamaruzaman (2011) A Study on the Short Run and long Run Determinants of Purchasing Power Parity in Malaysia. World Applied Science Journal, 12, 14-21

[9] Oznur Umit, A. (2016) Stationarity of Real Exchange Rates in the "Fragile Five": Analysis with Structural Breaks. International Journal of Economics and Finance, 8, 254-259. https://doi.org/10.5539/ijef.v8n4p254

[10] Levin, A., Lin, C.F. and Chu, C.S.J. (2002) Unit Root Tests in panel Data: Asymptotic and Finite-Sample Properties. Journal of Econometrics, 108, 1-24. https://doi.org/10.1016/S0304-4076(01)00098-7

[11] Im, K.S., Pesaran, M.H. and Shin, Y. (2003) Testing for Unit Roots in Heterogeneous Panels. Journal of Econometrics, 115, 53-74. https://doi.org/10.1016/S0304-4076(03)00092-7

[12] Breitung, J. (2000) The Local Power of Some Unit Root Tests for Panel Data. In: Baltagi, B., Ed., Nonstationary Panels, Panel Cointegration, and Dynamic Panels, Advances in Econometrics, Vol. 15, JAI, Amsterdam, 161-178. 
https://doi.org/10.1016/S0731-9053(00)15006-6

[13] Maddala, G.S. and Wu, S. (1999) A Comparative Study of Unit Root Tests with Panel Data and a New Simple Test. Oxford Bulletin of Economics and Statistics, 61, 631-652. https://doi.org/10.1111/1468-0084.61.s1.13

[14] Chaitip, P., Chaiboonsri, C. and Rangaswamy, N. (2008) A Panel Unit Root and Panel Cointegration Test of the Modeling International Tourism Demand in India. Annals of the University of Petroşani, Economics, 8, 95-124.

[15] Johansen, S. (1988) Statistical Analysis of Cointegration Vectors. Journal of Economic Dynamics and Control, 12, 231-254.

https://doi.org/10.1016/0165-1889(88)90041-3

[16] Fisher, R.A. (1932) Inverse Probability and the Use of Likelihood. Mathematical Proceedings of the Cambridge Philosophical Society, 28, 257-261.

https://doi.org/10.1017/S0305004100010094 